\title{
Farklı Düzeylerde Fosfor İçeren Bıldırcın (Coturnix coturnix japonica) Karma Yemlerine Esansiyel Yağ Karışımı İlavesinin Performans ve Bazı Organ Ağırlıklarına Etkisi
}

\author{
Ahmet Engin TÜZÜN1*, Turan AKDA $\breve{G}^{2}$ \\ ${ }^{1}$ Adnan Menderes Üniversitesi, Koçarlı Meslek Yüksekokulu Bitkisel ve Hayvansal Üretim Bölümü, Aydın \\ ${ }^{2}$ Necmettin Erbakan Üniversitesi, Seydişehir Meslek Yüksekokulu Bitkisel ve Hayvansal Üretim Bölümü, Konya \\ *İletişim (correspondence): e-posta atuzun@ adu.edu.tr; Tel: +90 (256) 7727348/115; Faks: +90 (256) 7117054 \\ Gönderim tarihi (Received): 11 Nisan 2016; Kabul tarihi (Accepted): 05 Temmuz 2016
}

$\ddot{O} \mathbf{z}$

$\mathrm{Bu}$ çalışma; farklı seviyelerde yararlanılabilir fosfor (YP) içeren karma yemlere esansiyel yağ karışımı (EYK) ilavesinin, Japon bıldırcınlarının (Coturnix coturnix japonica) besi performansı değerleri ve bazı organ ağırlıkları üzerine etkisini belirlemek amacıyla yürütülmüştür. Denemenin hayvan materyalini günlük yaşta ve karışık cinsiyette 480 adet Japon bıldırcın (Coturnix coturnix japonica) civcivi oluşturmuştur. Civcivler her biri 4 tekerrürden oluşan 4 muamele grubuna rastgele dağıtılmıştır. Muameleler; \%0.30 yararlanılabilir fosfor içerikli pozitif kontrol $(\mathrm{K}+), \% 0.18$ yararlanılabilir fosfor içerikli negatif kontrol (K-), pozitif kontrole EYK ilaveli $(\mathrm{K}+\mathrm{EYK})$ ve negatif kontrole EYK ilaveli (K-EYK) gruplardan oluşmaktadır. Pozitif kontrol grubuna EYK ilavesinin canlı ağırlık artışı (CAA) ve yemden yararlanma oranı (YYO) üzerinde istatistiki olarak önemli bir etkisi olmazken (P>0.05), yem tüketimini (YT) istatistiki olarak önemli seviyede azalttığı gözlemlenmiştir $(\mathrm{P}<0.05)$. Negatif kontrol grubuna EYK ilavesi ise CAA'nı istatistiki olarak önemli seviyede artırmış ( $\mathrm{P}<0.05)$, YT ve YYO'nı ise istatistiki olarak önemli seviyede azaltmıştır $(\mathrm{P}<0.05)$. Negatif kontrol grubunda karaciğer ağırlığı istatistiki olarak önemli seviyede artmıştır $(\mathrm{P}<0.05)$. Diğer taraftan karma yemlere EYK ilavesi karaciğer ağırlığını istatistiki olarak önemli seviyede azalttığı tespit edilmiştir $(\mathrm{P}<0.05)$. Kalp ağırlığı ise muamelelerden istatistiki olarak önemli seviyede etkilenmemiştir $(\mathrm{P}>0.05)$. Çalışmadan elde edilen sonuçlar düşük yararlanılabilir fosfor içeren bıldırcın karma yemlerinde EYK'nın performans artırıcı katkı maddesi olarak kullanılabileceğini göstermektedir.

Anahtar kelimeler: Fosfor, esansiyel yağ, bıldırcın, performans, organ ağırlığı

\section{The Effects of Essential Oil Mixture on Performance and Some Organ Weights in Japanese Quails (Coturnix coturnix japonica) Fed Diet Containing Different Levels of Phosphorous}

\begin{abstract}
The experiment were conducted to evaluate the effects of different levels of phosphorous containing dietary essential oil mixture supplementation (EOM) on the performance, and some organ weights of Japanese quails (Coturnix coturnix japonica). A total of 480 unsexed one-day-old Japanese quail chicks were used in the experiment. Four treatment was replicated four times in a completely randomized design. Treatments were positive control group was fed with ration containing $0.30 \%$ available phosphorus (AP), negative control group was fed with ration containing $0.18 \%$ available phosphorus (AP) and these essential oil mixture supplemented with consist of groups. The positive control group dietary EOM supplementation did not promote body weight gain (BWG) (P>0.05), while EOM supplementation decreased feed intake (FI) and feed conversion ratio (FCR) in the experiment $(\mathrm{P}<0.05)$. The negative control group dietary EOM supplementation promote body weight gain $(\mathrm{BWG})(\mathrm{P}<0.05)$, while $\mathrm{EOM}$ supplementation decreased feed intake $(\mathrm{FI})$ and feed conversion ratio $(\mathrm{FCR})$ in the experiment $(\mathrm{P}<0.05)$. The negative control group was significantly increased the liver weights $(\mathrm{P}<0.05)$. Supplementation diet with EOM significanly decreased liver weights $(\mathrm{P}<0.05)$. Heart weights was not effected by treatments $(\mathrm{P}>0.05)$. Overall results showed that an low available phosphorous including diets with EOM supplementation can be used as performance enhancer in Japanese quail diets.
\end{abstract}

Keywords: Phosphorous, essential oil, Japanese quail, performance, organ weight

\section{Giriş}

Hayvan organizmasinda esansiyel öneme sahip olan fosfor, yaşamsal öneminin yanı sıra iskelet dokusunun yapımı ve gelişiminde ayrıca birçok metabolik fonksiyonun gerçekleşmesinde son derece önemlidir
(Simons et al. 1990). Karma yemde enerji ve protein gereksinimlerinin karşılanmasından sonra gerek önem gerekse maliyet açısından üçüncü sırada yer almaktadır. Kanatlı karma yemlerinin önemli bir kısmını oluşturan tahıl ve küspelerdeki fosforun 2/3'ü bitkisel kökenli 
fitatlara (myo-inositol hekzakisfosfat) bağlı şekilde bulunmaktadır. Tek mideli hayvanlarda endojen kaynaklı fitaz enzimi miktarının yetersiz olması nedeniyle bitkisel kökenli yem maddelerinde fitat şeklinde bağlı bulunan fosforun 1/3'ünden daha azını değerlendirebilmektedir. $\mathrm{Bu}$ durum ekonomik ve çevresel açıdan oldukça önemli sonuçları da beraberinde getirir. Ayrıca bitkisel fitatların sindirilebilirliğinin düşük oluşunun protein ve mineral sindirimini de olumsuz yönde etkilediği bilinmektedir. Son yıllarda yapılan çalışmalarla fitatların sindirimi anlaşılmaya çalışılarak hayvanlar tarafından fitin fosforundan yararlanmanın iyileştirilmesi için gayret sarf edilmektedir. Son zamanlarda araştırmaların yoğunlaştığ konuların bir kısmında tıbbi ve aromatik bitkilerden elde edilen ekstratlar ve bunların esansiyel yağları gelmektedir. Genel olarak fitobiyotikler olarak adlandırılan bu alternatif yem katkı maddeleri tıbbi bitkilerin kök, yaprak, gövde, tohum ve çiçek gibi değişik organlarının ektraksiyonla ekstraktının çıkarılması veya su buharı distilasyonu ile esansiyel yağlarının çıkarılmasıyla elde edilmektedir. Esansiyel yağların içermiş olduğu değişik etken maddelerin etki mekanizmaları (antimikrobiyal, antioksidant, antifungal, antiparaziter, enzimatik, immunostimulatör vb) yapılan in vivo ve in vitro çalışmalarla ayrıntılı biçimde açıklanmaya çalışılmaktadır. Esansiyel yağların belirtilen genel etkilerinin yanı sıra etlik piliçlerin karma yemlerine ilavesi ile yemde lezzet artışı, sindirimin uyarılması, sindirim enzimlerinin etkinliğinin artırılması, bağırsaklarda patojen mikroorganizmaların baskılanarak sindirim ve sağlık açısından uygun bir mikrofloranın oluşması ve protein sentezini uyararak daha kaliteli ve düşük kolesterollü hayvansal ürün üretme gibi faydalar da sağladığı bildirilmektedir (Gill, 1999). Ayrıca Amad ve ark. (2011) broyler karma yemlerine esansiyel yă ilavesinin ileal yağ, protein ve fosfor sindirilebilirliğini sırasıyla \%3, 9 ve 15.9 oranında artırdı ğını bildirmiştir. Bu bildirişlerden yola çıkarak mevcut çalışmada farklı seviyelerde yararlanılabilir fosfor içeren karma yemlere esansiyel yağ karışımı (EYK) ilavesinin Japon bıldırcınların besi performansı ve bazı organ ağırlıklarına etkisi incelenmiştir.

\section{Materyal ve Yöntem}

Adnan Menderes Üniversitesi Koçarlı Meslek Yüksekokulu Kanatlı Ünitesinde yürütülen bu araştırmada günlük yaşta ve karışık cinsiyette 480 adet Japon bıldırcın (Coturnix coturnix japonica) civcivi kullanılmıştır. Civcivler her birinde 30 (15 erkek+15 dişi) hayvan olan 4 tekerrürlü 4 muamele grubuna tesadüfi olarak dağıtılmıştır. Deneme batarya tipi kafeslerde $(62 \times 123 \times 28$ $\mathrm{cm})$ yürütülmüştür. Denemenin birinci gününde oda sicaklığ 1 termostatlı 1 sitıcılar ile $33^{\circ} \mathrm{C}$ ayarlanmış ve denemenin 21. gününde $22^{\circ} \mathrm{C}$ olacak şekilde kademeli olarak düşürülerek deneme sonuna (35 günlük yaşa) kadar bu sıcaklıkta tutulmuştur. Civcivlere yem ve su ad-libitum olarak verilmiştir. Denemede; 0-3. gün 23 saat, 4-14. gün 20 saat, 15-35. gün 18 saat aydınlatma programı uygulanmıştır.

Denemede misır-soya küspesi esaslı toz karma yem izokalorik ve izonitrojenik olarak hazırlanmıştır. Denemede NRC (1994)'de belirtilen besin maddelerini (\%24 HP, $2900 \mathrm{kcal} \mathrm{ME} / \mathrm{kg}$ ) içeren ve yararlanılabilir fosfor (YP) seviyesi \%0.30 (pozitif kontrol, $\mathrm{K}+$ ) ve yararlanılabilir fosfor seviyesi $\% 0.18$ (negatif kontrol, K) olan iki farklı temel karma yem hazırlanmıştır. Bu iki temel karma yeme esansiyel yağ karışımı (EYK) ilave edilmiştir. Ticari esansiyal yağ karışımı (EYK) yerli bir ürün olup (Herbromix ${ }^{\circledR}$-Herba A.Ş. İzmir), altı farklı esansiyel yağın karışımından oluşmuştur (kekik, defne, rezene, ada çayı, mersin yaprağı ve portakal kabuğu yağı). Denemede kullanılan EYK'1nda bulunan major aktif madde bileşenleri karvakrol (\%58.6), 1,8-sineol $(\% 14.3)$ ve timol (\%5)'dür. Esansiyel yağ karışımı laboratuar tipi mikserde bitkisel yağ içerisinde homojenize edilerek karma yeme $90 \mathrm{mg} / \mathrm{kg}$ düzeyinde ilave edilmiştir. Temel karmalara EYK ilavesi ile; pozitif kontrole EYK ilaveli $(\mathrm{K}(+) \mathrm{EYK})$ ve negatif kontrole EYK ilaveli (K(-)EYK) karma yemler oluşturulmuştur. Hazırlanan karma yemler ağzı kapaklı kovalarda muhafaza edilmiştir. Deneme kullanılan karma yemlerin bileşimi ve hesaplanmış besin madde kompozisyonu Çizelge 1'de verilmiştir.

Bıldırcınların canlı ağırlıkları ve verilen yem miktarı haftalık yapılan ölçümler ile belirlenmiş ve elde edilen değerlerden canlı ağırlık artışı ve yemden yararlanma oranı hesaplanmıştır. Deneme süresince ölen bıldırcınlar günlük olarak kaydedilerek yemden yararlanma oranının hesaplanmasında dikkate alınmıştır. Deneme sonunda grup ortalamalarına benzer ağırlıkta her gruptan 16 adet (8 Erkek ve 8 Dişi) olmak üzere toplam 64 adet bıldırcın kesilmiştir. Kesim için ayrılan bıldırcınlar kesimden önce 10 saat aç bırakılarak sindirim kanalının boşalması sağlanmıştır. Kesim esnasında bıldırcınlardan çıkarılan iç organlar (karaciğer ve kalp) tartılarak canlı ağırlığa bölünmüş ve oransal ağırlıkları belirlenmiştir.

Denemeden elde edilen verilerin analizi, tesadüf parselleri deneme deseninde faktöriyel düzene göre 4 tekerrürlü olarak SAS (2001) istatistik paket programı kullanarak yapılmıştır. Yüzde (\%) ile tanımlanan veriler, değerlendirilmeden önce arc-sine transformasyonuna tabi tutulmuştur. Gruplar arasındaki farklılıkların önemlilik kontrolü $\mathrm{t}$ testi ile yapılmıştır. Veriler arasındaki farklılıklar $\mathrm{P}<0.05$ düzeyinde anlamlı olarak değerlendirilmiştir. 
Çizelge 1. Deneme karma yemlerinin hammadde ve hesaplanmış besin madde kompozisyonları (\%)

\begin{tabular}{lcc}
\hline & YP \%0.30 & YP \%0.18 \\
\hline Hammaddeler & & \\
Misır & 45.09 & 44.55 \\
Soya küspesi & 43.00 & 43.00 \\
Buğday kepeği & 5.00 & 5.00 \\
Bitkisel yağ & 4.10 & 4.90 \\
Mermer tozu & 1.35 & 1.77 \\
Dikalsiyum Fosfat & 0.66 & - \\
Tuz & 0.25 & 0.23 \\
Premiks ${ }^{1}$ & 0.25 & 0.25 \\
Metiyonin & 0.30 & 0.30 \\
& 100.00 & 100.00 \\
\hline Hesaplanmış besin madde kompozisyonu & & \\
Metabolik enerji, MJ/kg ${ }^{2}$ & 12.16 & 12.16 \\
Ham protein & 24.08 & 24.03 \\
Lisin & 1.33 & 1.33 \\
Metiyonin & 0.57 & 0.56 \\
Metiyonin + Sistin & 1.06 & 1.05 \\
Kalsiyum & 0.80 & 0.80 \\
Toplam Fosfor & 0.58 & 0.46 \\
Yararlanılabilir Fosfor & 0.30 & 0.18 \\
\hline
\end{tabular}

${ }^{1}$ Karma yemin her kilogramı; Mangan: 60 mg; Demir: $30 \mathrm{mg}$; Bakır: 5 mg; Selenyum: $0.1 \mathrm{mg}$, Vitamin A, 8.800 IU; Vitamin D3, 2.200 IU; Vitamin E, 11 mg; Nicotin Amid, 44 mg; Kalsiyum D-pantotenat, 8.8 mg; Riboflavin 4.4 mg; Tiamin 2.5 mg; Vitamin $\mathrm{B}_{12}$, $6.6 \mathrm{mg}$; Folik asit, $1 \mathrm{mg}$; D-Biyotin, $0.11 \mathrm{mg}$; Kolin: $220 \mathrm{mg}$ içermektedir.

${ }^{2}$ Denemede kullanılan karma yemlerin metabolik enerji (ME) düzeyleri TSE (1991)'deki gibi hesaplanmıştır.

\section{Bulgular}

\section{Performans}

Farklı düzeylerde YP içeren karmalara EYK ilavesinin bıldırcınların canlı ağırlık (CA), canlı ağılık artışı (CAA), yem tüketimi (YT) ve yemden yararlanma oranına etkisi (YYO) Çizelge 2'de verilmiştir. Denemenin birinci haftasında (0-7. gün) canlı ağırlık ve canlı ağırlık artışı bakımından gruplar arasında bir farklılık bulunmamıştır $(\mathrm{P}>0.05)$. Bu dönemde yem tüketimi bakımından K-EYK, $\mathrm{K}+\mathrm{ve} \mathrm{K}+\mathrm{EYK}$ grupları arasında farkl11 lk bulunmazken, en düşük yem tüketimi $31.75 \mathrm{~g}$ ile $\mathrm{K}$ - grubunda olmuştur $(\mathrm{P}<0.05)$. Yemden yararlanma oranı bakımından ise; $\mathrm{K}$ EYK ve $\mathrm{K}+$ grupları arasinda farklılık bulunmazken, en düşük yemden yararlanma oranı 1.95 ile $\mathrm{K}+\mathrm{EYK}$ grubunda en yüksek yemden yararlanma oranı ise 2.37 ile $\mathrm{K}$ - grubunda olmuştur $(\mathrm{P}<0.05)$. Denemenin ikinci haftasında (7-14. gün) ise canlı ağırlık ve canlı ağırlık artıșı bakımından gruplar arasında bir farklılık bulunmamıştır ( $\mathrm{P}>0.05$ ). Bu dönemde $78.45 \mathrm{~g}$ ile $\mathrm{K}+$ grubu en yüksek, $64.35 \mathrm{~g}$ ile K-EYK grubu en düşük yem tüketimine sahip olmuştur. Yemden yararlanma oranı bakımından ise K-, $\mathrm{K}+\mathrm{ve} \mathrm{K}+\mathrm{EYK}$ grupları arasında farklılık bulunmazken, en düşük yemden yararlanma oran 1.76 ile K-EYK grubunda olmuştur $(\mathrm{P}<0.05)$. Denemenin üçüncü haftasında (14-21. gün) canlı ağırlık bakımından $\mathrm{K}-\mathrm{EYK}, \mathrm{K}+$ ve $\mathrm{K}+\mathrm{EYK}$ grupları arasında bir farklılık bulunmamıştır $(\mathrm{P}>0.05)$.
Ancak $97.87 \mathrm{~g}$ ile en düşük canlı ağılık K- grubunda olmuştur $(\mathrm{P}<0.05)$. Bu dönemde $\mathrm{K}-, \mathrm{K}+$ ve $\mathrm{K}+\mathrm{EYK}$ grupları arasında canlı ağırlık artışı bakımından farklılık bulunmazken, en düşük canlı ağırlık artış $39.70 \mathrm{~g}$ ile KEYK grubunda olmuştur $(\mathrm{P}<0.05)$. Yem tüketimi ve yemden yararlanma oranı bakımından ise gruplar arasında farklılık olmamıştır $(\mathrm{P}>0.05)$. Denemenin dördüncü haftasında (21-28. gün) canlı ağırlık bakımından K-EYK, $\mathrm{K}+$ ve $\mathrm{K}+\mathrm{EYK}$ grupları arasında bir farklı1 bulunmamıştır $(\mathrm{P}>0.05)$. Ancak $134.27 \mathrm{~g}$ ile en düşük canlı ağırlık K- grubunda olmuştur $(\mathrm{P}<0.05)$. Canlı ağırlık artışı bakımından ise gruplar arasında bir farklılık bulunmamıştır $(\mathrm{P}>0.05)$. Bu dönemde yem tüketimi ve yemden yararlanma oranı bakımından $\mathrm{K}-, \mathrm{K}+\mathrm{ve} \mathrm{K}+\mathrm{EYK}$ grupları arasında bir farklılık bulunmazken, en düşük yem tüketimi ve yemden yararlanma oranı sirasiyla $130.82 \mathrm{~g}$ ve 3.40 ile K-EYK grubunda olmuştur $(\mathrm{P}<0.05)$. Denemenin beşinci haftasında (28-35. gün) canlı ağırlık bakımından $\mathrm{K}-\mathrm{EYK}, \mathrm{K}+$ ve $\mathrm{K}+\mathrm{EYK}$ grupları arasında bir farklılık bulunmamıştır $(\mathrm{P}>0.05)$. Ancak 164.15 g ile en düşük canlı ağırlık K- grubunda olmuştur $(\mathrm{P}<0.05)$. Canlı ağırlık artışı ve yemden yararlanma oranı bakımından ise gruplar arasında bir farklılık bulunmamıştır $(\mathrm{P}>0.05) . \mathrm{Bu}$ dönemde yem tüketimi bakımından $\mathrm{K}-$, $\mathrm{K}+$ ve $\mathrm{K}+\mathrm{EYK}$ grupları arasında bir farklılık olmazken, en düşük yem tüketimi $149.65 \mathrm{~g}$ ile K-EYK grubunda olmuştur $(\mathrm{P}<0.05)$. Denemenin sonucunda (0-35. gün) canlı ağırlık artı̧̧1 
bakımından $\mathrm{K}+$ ve $\mathrm{K}+\mathrm{EYK}$ grupları arasında bir farklılık bulunmamıştır $(\mathrm{P}>0.05)$. En düşük canlı ağırlık artışı $156.73 \mathrm{~g}$ ile $\mathrm{K}-$ grubunda bulunmuştur $(\mathrm{P}<0.05)$. Yem tüketimi bakımından ise $\mathrm{K}$ - ve $\mathrm{K}+\mathrm{EYK}$ grupları arasında bir farklıl1k bulunmazken, $541.51 \mathrm{~g}$ ile en yüksek yem tüketimi $\mathrm{K}+$ grubunda, $488.01 \mathrm{~g}$ ile en düşük yem tüketimi K-EYK grubunda bulunmuştur $\quad(\mathrm{P}<0.05)$. Deneme sonucunda yemden yararlanma oranı bakımından ise en düşük yemden yararlanma oranı 3.01 ile K-EYK grubunda, en yüksek yemden yararlanma oranı 3.30 ile $\mathrm{K}$ - grubunda bulunmuştur $(\mathrm{P}<0.05)$.

Çizelge 2. Farklı düzeylerde fosfor içeren bıldırcın karmalarına esansiyel yă̆ karışımı ilavesinin canlı ağırlık (CA; g), canlı ağırlık artı̧̧ı (CAA; g), yem tüketimi (YT; g) ve yemden yararlanma oranına (YYO; g, yem tüektimi/g canlı ağırlık artışı) etkisi

\begin{tabular}{|c|c|c|c|c|c|c|}
\hline Haftalar & K-1 & K-EYK & $\mathbf{K}+$ & K+EYK & SHO $^{2}$ & P Değeri \\
\hline \multicolumn{7}{|l|}{ 1.Hafta } \\
\hline Baş.CA & 7.42 & 7.48 & 7.55 & 7.45 & 0.075 & 0.8698 \\
\hline $\mathrm{CA}(\mathrm{g})$ & 20.82 & 23.25 & 23.62 & 25.05 & 1.11 & 0.1119 \\
\hline CAA (g) & 13.40 & 15.77 & 16.07 & 17.60 & 1.10 & 0.1082 \\
\hline YT (g) & $31.75^{\mathrm{b}^{*}}$ & $35.67^{\mathrm{a}}$ & $34.12^{\mathrm{a}}$ & $34.27^{\mathrm{a}}$ & 0.79 & 0.0300 \\
\hline YYO & $2.37^{\mathrm{a}}$ & $2.26^{\mathrm{b}}$ & $2.12^{\mathrm{b}}$ & $1.95^{\mathrm{c}}$ & 0.030 & 0.0037 \\
\hline \multicolumn{7}{|l|}{ 2.Hafta } \\
\hline$\overline{\mathrm{CA}(\mathrm{g})}$ & 56.22 & 59.82 & 61.47 & 61.10 & 1.43 & 0.0853 \\
\hline CAA (g) & 35.40 & 36.57 & 37.85 & 36.05 & 0.91 & 0.3390 \\
\hline $\mathrm{YT}(\mathrm{g})$ & $69.00^{\mathrm{bc}}$ & $64.35^{\mathrm{c}}$ & $78.45^{\mathrm{a}}$ & $73.95^{\mathrm{b}}$ & 3.00 & 0.0315 \\
\hline YYO & $1.95^{\mathrm{a}}$ & $1.76^{\mathrm{b}}$ & $2.07^{\mathrm{a}}$ & $2.05^{\mathrm{a}}$ & 0.078 & 0.0313 \\
\hline \multicolumn{7}{|l|}{ 3.Hafta } \\
\hline$\overline{\mathrm{CA}(\mathrm{g})}$ & $97.87^{\mathrm{b}}$ & $99.52^{\mathrm{ab}}$ & $103.82^{\mathrm{a}}$ & $103.90^{\mathrm{a}}$ & 1.63 & 0.0500 \\
\hline $\mathrm{CAA}(\mathrm{g})$ & $41.65^{\mathrm{a}}$ & $39.70^{\mathrm{b}}$ & $42.35^{\mathrm{a}}$ & $42.80^{\mathrm{a}}$ & 0.59 & 0.0164 \\
\hline YT (g) & 113.55 & 107.52 & 116.02 & 117.47 & 3.60 & 0.2699 \\
\hline YYO & 2.73 & 2.71 & 2.74 & 2.74 & 0.082 & 0.9916 \\
\hline \multicolumn{7}{|l|}{ 4.Hafta } \\
\hline $\mathrm{CA}(\mathrm{g})$ & $134.27^{b}$ & $137.97^{\mathrm{ab}}$ & $142.67^{\mathrm{a}}$ & $142.30^{\mathrm{a}}$ & 1.68 & 0.0126 \\
\hline $\mathrm{CAA}(\mathrm{g})$ & 36.40 & 38.45 & 38.85 & 38.40 & 0.69 & 0.1096 \\
\hline YT (g) & $141.05^{\mathrm{a}}$ & $130.82^{b}$ & $145.87^{\mathrm{a}}$ & $143.32^{\mathrm{a}}$ & 2.70 & 0.0099 \\
\hline YYO & $3.88^{a}$ & $3.40^{\mathrm{b}}$ & $3.75^{\mathrm{a}}$ & $3.73^{\mathrm{a}}$ & 0.099 & 0.0344 \\
\hline \multicolumn{7}{|l|}{ 5.Hafta } \\
\hline$\overline{\mathrm{CA}(\mathrm{g})}$ & $164.15^{b}$ & $169.45^{\mathrm{ab}}$ & $175.05^{\mathrm{a}}$ & $172.22^{\mathrm{a}}$ & 5.16 & 0.0391 \\
\hline CAA (g) & 29.88 & 31.48 & 32.38 & 29.92 & 1.79 & 0.5720 \\
\hline YT $(\mathrm{g})$ & $161.40^{\mathrm{a}}$ & $149.65^{b}$ & $167.05^{\mathrm{a}}$ & $154.72^{\mathrm{ab}}$ & 6.34 & 0.0487 \\
\hline YYO & 5.40 & 4.75 & 5.16 & 5.17 & 0.42 & 0.9262 \\
\hline \multicolumn{7}{|l|}{ 0-5.Hafta } \\
\hline$\overline{\mathrm{CAA}(\mathrm{g})}$ & $156.73^{\mathrm{c}}$ & $161.97^{b}$ & $167.50^{\mathrm{a}}$ & $164.77^{\mathrm{a}}$ & 2.19 & 0.0410 \\
\hline $\mathrm{YT}(\mathrm{g})$ & $516.75^{\mathrm{b}}$ & $488.01^{\mathrm{c}}$ & $541.51^{\mathrm{a}}$ & $523.73^{b}$ & 8.21 & 0.0407 \\
\hline YYO & $3.30^{\mathrm{a}}$ & $3.01^{\mathrm{c}}$ & $3.23^{\mathrm{ab}}$ & $3.18^{\mathrm{b}}$ & 0.070 & 0.0260 \\
\hline
\end{tabular}

*a-c Aynı satırda farklı harfle gösterilen ortalamalar arasındaki farklar önemlidir ( $\mathrm{P}<0.05) .{ }^{1}(\mathrm{~K}-)$ : \%0.18 Yararlanılabilir fosfor içerikli negatif kontrol, (K-EYK): Negatif kontrol esansiyel yağ karışımı ilaveli, $(\mathrm{K}+)$ : \%0.30 Yararlanılabilir fosfor içerikli pozitif kontrol, (K+EYK): Pozitif kontrol esansiyel yağ karışımı ilaveli. ${ }^{2} \mathrm{SHO}$ :Standart hata ortalaması.

\section{Organ Ăğrlıklart}

Farklı düzeylerde YP içeren karmalara EYK ilavesinin bıldırcınların karaciğer ve kalp ağırlıklarına etkisi Çizelge 3'de verilmiştir. Muamelelerin ve cinsiyetin karaciğer ağırlı̆̆ına etkisi önemli bulunmuştur $(\mathrm{P}<0.05)$. Karaciğer ağırlığı bakımından K-EYK ve $\mathrm{K}+$ grupları arasında önemli bir farklılık bulunmazken, en düşük karaciğer ağırlığı $\mathrm{K}+\mathrm{EYK}$ grubunda en yüksek karaciğer ağırlığı ise K- grubunda bulunmuştur. Dişi bıldırcınların canlı ağırlığı ve karaciğer ağırlığı erkek bıldırcınlarınkinden önemli oranda yüksek bulunmuştur $(\mathrm{P}<0.05)$. Muamelelerin kalp ağırlı̆̆ına etkisi önemli bulunmamıştır $(\mathrm{P}>0.05)$. Ancak cinsiyetin kalp ağırlığına etkisi önemli bulunmuştur $(\mathrm{P}<0.05)$. Kalp ağırlığ bakımından erkek bıldırcınların kalp ağırlı̆̆ı dişi bıldırcınların kalp ağırlığından önemli oranda yüksek bulunmuştur $(\mathrm{P}<0.05)$. 
Çizelge 3. Farklı düzeylerde yararlanılabilir fosfor içeren bıldırcın karma yemlerine esansiyel yağ karışımı ilavesinin bazı organ ağırlıklarına etkisi (\%)

\begin{tabular}{lccc}
\hline & Canlı Ă̆ırlık & Karaciğer, \% & Kalp, \% \\
\hline Muamele & & & \\
K-1 $^{1}$ & $164.15^{\mathrm{b}^{*}}$ & $2.71^{\mathrm{a}}$ & 0.83 \\
K-EYK & $169.45^{\mathrm{ab}}$ & $2.41^{\mathrm{b}}$ & 0.84 \\
K+ & $175.05^{\mathrm{a}}$ & $2.43^{\mathrm{b}}$ & 0.85 \\
K+EYK & $172.22^{\mathrm{a}}$ & $2.23^{\mathrm{c}}$ & 0.87 \\
SHO $^{2}$ & 5.16 & 0.39 & 0.08 \\
Cinsiyet & & & \\
Erkek & $155.03^{\mathrm{b}}$ & $1.99^{\mathrm{b}}$ & $0.94^{\mathrm{a}}$ \\
Dişi & $181.72^{\mathrm{a}}$ & $2.90^{\mathrm{a}}$ & $0.75^{\mathrm{b}}$ \\
SHO & 8.32 & 0.88 & 0.15 \\
\hline \multicolumn{3}{c}{ P değeri } \\
\hline Muamele & 0.0391 & 0.0462 & 0.4150 \\
Cinsiyet & 0.0001 & 0.0001 & 0.0380 \\
Muamele*Cinsiyet & 0.4882 & 0.9627 & 0.0864 \\
\hline
\end{tabular}

*a-c Aynı satırda farklı harfle gösterilen ortalamalar arasındaki farklar önemlidir $(\mathrm{P}<0.05) .{ }^{1}(\mathrm{~K}-)$ : \%0.18 Yararlanılabilir fosfor içerikli negatif kontrol, (K-EYK): Negatif kontrol esansiyel yağ karışımı ilaveli, (K+): \%0.30 Yararlanılabilir fosfor içerikli pozitif kontrol, (K+EYK): Pozitif kontrol esansiyel yağ karışımı ilaveli. ${ }^{2} \mathrm{SHO}$ :Standart hata ortalaması

\section{Tartışma ve Sonuç}

Elde edilen sonuçlar göre; düşük YP seviyesindeki karma yemlere EYK ilavesi CAA'nı olumlu yönde etkilemiş $(\mathrm{P}<0.05)$, normal YP seviyesindeki karma yemlere EYK ilavesi ise CAA üzerinde olumlu bir etki sağlamamıştır ( $\mathrm{P}>0.05)$. Elde edilen sonuçlar; Botsoglou ve ark. (2002), Lee ve ark. (2003), Jang ve ark. (2007), Aksu ve Bozkurt (2009)'un broyler karma yemine EYK ilavesinin CAA bakımından olumlu bir etkisinin olmadığını bildirdiği çalışmalar ile uyumluluk göstermektedir. Temel karma yemlere EYK ilavesi YT'ni önemli seviyede azaltmıştır $(\mathrm{P}<0.05)$. Elde edilen sonuçlar; Alçiçek ve ark. (2003), Basmacioğlu ve ark. (2004), Çabuk ve ark. (2006), Amad ve ark. (2011), Mountzouris ve ark. (2011), Agostini ve ark. (2012)'nın broyler karma yemine EYK ilavesinin YT’i azalttığını bildirdiği çalışmalar ile uyumludur. Temel karma yemlere EYK ilavesi YYO'nı önemli seviyede azaltmıştır $(\mathrm{P}<0.05)$. Düşük $\mathrm{YP}$ seviyesindeki karma yemlere EYK ilavesi YYO'nı olumlu yönde etkilemiş $(\mathrm{P}<0.05)$, normal $\mathrm{YP}$ seviyesindeki karma yemlere EYK ilavesinin YYO'nındaki sağladığı iyileşme ise sayısal düzeyde kalmıştır $(\mathrm{P}>0.05)$. Elde edilen sonuçlar; Jamroz ve ark. (2003), Ertaş ve ark. (2005), Çabuk ve ark. (2006), Tiihonen ve ark. (2010), Amad ve ark. (2011), Amerah ve ark. (2011), Mountzouris ve ark. (2011), Agostini ve ark. (2012)'nın broyler karma yemine EYK ilavesinin YYO’ı iyileştirdiğini bildirdiği çalışmalar ile uyumludur.

Mevcut denemede düşük YP içeren karma yemlerinin CAA'nı önemli seviyede azalttığı bulunmuştur $(\mathrm{P}<0.05)$. Elde edilen sonuçlar; Fernandes ve ark.(1999), Sohail ve Roland (1999), Bozkurt ve ark. (2006), Mondal ve ark. (2007), Akyürek ve ark. (2009), El-Sherbiny ve ark. (2010)'ın broyler karma yemlerinde düşük YP seviyesinin CAA'nı azalttığını bildirdiği çalışmalar ile uyumludur. Mevcut denemede düşük YP içeren broyler karma yemlerinin YT'ni önemli seviyede azalttığ bulunmuştur $(\mathrm{P}<0.05)$. Elde edilen sonuçlar; $\mathrm{Li}$ ve ark.(2000), Akyürek ve ark. (2009), Jamal M. Abo Omar ve Rabie Sabha (2009), El-Sherbiny ve ark. (2010)'ın broyler karma yemlerinde düşük YP seviyesinin YT'ni azalttığını bildirdiği çalışmalar ile uyumludur. Mevcut denemede düşük YP içeren broyler karma yemlerinin YYO'nı önemli seviyede etkilemediği bulunmuştur $(\mathrm{P}<0.05)$. Elde edilen sonuçlar; Nelson ve ark. (1990), Konca ve Yazgan (2002), Ebrahimi ve ark. (2015) broyler karma yemlerinde düşük YP seviyesinin YYO'nı önemli seviyede etkilemediğini bildirdiği çalışmalar ile uyumludur.

Çizelge 3'de deneme sonunda kesilen hayvanların karaciğer ve kalp ağırlıkları (\%) gösterilmiştir. Temel karma yemlere EYK ilavesi karaciğer ağırlığını önemli seviyede azaltmıştır $(\mathrm{P}<0.05)$. Düşük YP seviyesindeki karma yemler ise karaciğer ağırlı̆̆ını önemli seviyede artırmıştır $(\mathrm{P}<0.05)$. Bu sonuçlar ile Viveros ve ark. (2002) ve Tatlı (2007)'nın broyler karma yemlerinde düşük YP seviyesinin karaciğer ağırlığını önemli seviyede artırdığını bildirdiği çalışma ile uyumludur. Ayrıca dişi bıldırcınların karaciğer ağırlığı erkek bıldırcınların karaciğer ağırlığından önemli seviyede yüksek bulunmuştur $(\mathrm{P}<0.05)$. Muamelelerin kalp ağırlığına önemli bir etkisi olmamıştır ( $\mathrm{P}>0.05)$. Ancak erkek bıldırcınların kalp ağırlığı dişi bıldırcınların kalp ağırlığından önemli seviyede yüksek bulunmuştur $(\mathrm{P}<0.05)$. 
Sonuç olarak; esansiyel yağların ileal sindirilebilirliği önemli düzeyde yükselterek yemin sindirilebilirliğini artırdığı ve dolayısıyla etlik piliçlerin yemden yararlanma kabiliyetini iyileştirdiği birçok çalışmada bildirilmiştir (Madrid ve ark. 2003, Jamroz ve ark. 2003, Amad ve ark. 2011, Mountzouris ve ark. 2011). Mevcut çalışmada da düşük YP içeren karma yeme ilave edilen EYK'ı bıldırcınların CAA, YT ve YYO değeri üzerinde sağladığı önemli iyileşmeyi EYK'nın sahip olduğu antimikrobiyal etki ve endojen sindirim enzimlerinin etkinliğini, büyük olasılıkla endojen fitaz enzimi etkinliğini artırarak besin madde sindirilebilirliğini artırdığ1 düşünülmektedir. Özellikle düşük yararlanılabilir fosfor (YP) içeren karma yeme EYK ilavesi sonucunda yemden yararlanma değerindeki önemli iyileşmenin esansiyel yağların belirtilen aktivitelerinin yanı sıra, fitin fosforun bazı mineraller ve amino asitler ile yaptığı çözünmez bileşiklerin oluşumunun EYK'nın sağladığı biyoaktif bileşikler tarafindan bir ölçüde engellenmesinden kaynaklandığ düşünülmektedir. Esansiyel yağların mineral madde sindirilebilirliğine sağlayacağı katkı günümüzün önemli problemlerinden biri olan çevre kirliliğinin azaltılmasında etkili olacağı ve karma yem maliyetinde bir miktar azalma sağlayabileceği ve esansiyel yağların besin maddeleri ile mineral madde sindirilebilirliği açısından potansiyelinin daha detaylı çalışmalarla ortaya konulması gerektiği kanaatine varılmıştır.

\section{Kaynaklar}

Aksu T, Bozkurt AS. 2009. Effect of dietary essential oils and/or humic acids on broiler performance, microbial population of intestinal content and antibody titres in the summer season. Kafkas Üniversitesi Veteriner Fakültesi Dergisi 15(2):185-190.

Akyürek H, Okur AA, Samlı HE. 2009. Impacts of phytase and/or carbohydrases on performance, intestinal organs and bone development in broilers fed wheat-based diets containing different levels of phosphorus. Journal of Animal and Veterinary Advances 8(7): 1432-1437.

Agostini PS, Sola-Oriol D, Nofrarias M, Barroeta AC, Gasa J, Manzanilla EG. 2012. Role of in-feed clove supplementation on growth performance, intestinal microbiology, and morphology in broiler chicken. Livesock Science 147:113-118.

Amad AA, Manner K, Wendler KR, Neumann K, Zentek J. 2011. Effects of a phytogenic feed additive on growth performance and ileal nutrient digestibility in broiler chickens. Poultry Science 90:2811-2816.
Amerah AM, Peron A, Zaefarian F, Ravindran V. 2011. Influence of whole wheat inclusion and a blend of essential oils on the performance, nutrient utilization, digestive tract development and ileal microbiota profile of broiler chickens. British Poultry Science 52:124-132.

Alçiçek A, Bozkurt M, Çabuk M. 2003. The effect of an essential oil combination derived from selected herbs growing wild in Turkey on broiler performance. South African Journal of Animal Science 33:89-94.

Alçiçek A, Bozkurt M, Çabuk M. 2004. The effect of a mixture of herbal essential oils, an organic acid or a probiotic on broiler performance. South African Journal of Animal Science 34: 217-222.

Basmacioğlu H, Tokuşoğlu O, Ergül M. 2004. The effect of oregano and rosemary essential oils or alphatocopheryl acetate on performance and lipid oxidation of meat enriched with n-3 PUFA's in broilers. South African Journal of Animal Science 34: 197-210.

Botsoglou NA, Florou-Paneri P, Christaki E, Fletouris DJ, Spais AB. 2002. Effect of dietary oregano essential oil on performance of chickens and on iron-induced lipid oxidation of breast, thigh and abdominal fat tissues. British Poultry Science 43:223-230.

Bozkurt M, Çabuk M, Alçiçek A. 2006. The effect of microbial phytase in broiler grower diets containing low phosphourus, energy and protein. The Journal of Poultry Science 43:29-34.

Çabuk M, Bozkurt M, Alçiçek A, Akbaş Y, Küçükyılmaz K. 2006. Effect of a herbal essential oil mixture on growth and internal organ weight of broilers from young and old breeder flocks. South African Journal of Animal Science 36:135-141.

Ebrahimi H, Shariatmadari F, Karimi Torshizi MA. 2015. Dietary supplementation and in ovo injection of $1 \alpha$ OHD3 in a low-calcium and low phosphorous diets for broilers. Journal of Applied Animal Research 44(1):113-117.

El-Sherbiny AE, Hassan HMA, Abd-Elsamee MO, Samy A, Mohamed MA. 2010. Performance, bone parameters and phosphorus excretion of broiler fed low phosphorus diets supplemented with phytase from 23 to 40 days of age. International Journal of Poultry Science 9(10):972-977.

Ertaş ON, Güler T, Çiftçi M, Dalkılıç B, Şimşek G. 2005. The effect of an essential oil mix derived from oregano, clove and anise on broiler performance. International Journal of Poultry Science 4(11):879884. 
Fernandes JIM, Lima FR, Mendonca JR.CX, Mabe I, Albuquerque R, Leal PM. 1999. Relative bioavability of phosphorus in feed and agricultural phosphates for poultry. Poultry Science 78:1729-1736.

Giil C. 1999. Herbs and plant extracts as growth enhancers. Feed International 4:20-23.

Jamal M. Abo Omar, Rabie Sabha. 2009. Effects of phytase on broilers performance and body status of phosphorus. Hebron University Research Journal 4(1):55-66.

Jamroz D, Orda J, Kamel C, Wiliczkiewicz A, Wertelecki T, Skorupinska J. 2003. The influence of phytogenic extracts on performance, nutrient digestibility, carcass characteristics, and gut microbial status in broiler chickens. Journal of Animal Feed Science 12:583-596.

Jang IS, Ko YH, Kang SY, Lee, CY. 2007. Effect of commercial essential oils on growth performance, digestive enzyme activity and intestinal microflora population in broiler chickens. Animal Feed Science Technology 134:304-315.

Konca Y, Yazgan O. 2002. Fosfor seviyesi farklı rasyonların etlik piliçlerin farklı büyüme dönemlerinde besi performansı ve bazı kemik özelliklerine etkileri. Selçuk Üniversitesi Ziraat Fakültesi Dergisi 16(29):48-52.

Lee KW, Everts H, Kappert HJ, Frehner M, Losa R, Beynen AC. 2003. Effects of dietary essential oil components on growth performance, digestive enzymes and lipid metabolism in female broiler chickens. British Poultry Science 44:450-457.

Li YC, Ledoux DR, Veum TL, Raboy V, Ertl DS. 2000. Effects of low phytic acid corn on phosphorus utilization, performance and bone mineralization in broiler chicks. Poultry Science 79:1444-1450.

Madrid J, Hernandez F, Garcia V, Orengo J, Megias MD, Sevilla V. 2003. Effect of plant extracts on ileal apparent digestibility and carcass yield in broilers at level of farm. European Symposium Poultry Nutrition, 14th, August, Lillehammer, Norway, p.187-188.

Mondal MK, Panda S, Biswas P. 2007. Effect of microbial phytase in soybean meal based broiler diets containing low phosphorous. International Journal of Poultry Science 6(3):201-206.

Mountzouris K, Paraskeyas V, Tsirtsikos P, Palamidi I, Steiner T, Schatzmayr G, Fegeros K. 2011. Assessment of a phytogenic feed additive effect on broiler growth performance, nutrient digestibility and caecal microflora composition. Animal Feed Science Technology 168:223-231.

Nelson TS, Kirby LK, Johnson ZB. 1990. Effect of minerals on the incidence of leg abnormalities in growing broiler chicks. Nutrition Research 10:525533.

NRC. 1994. Nutrient Requirements of Poultry. $9^{\text {th }}$ rev.ed. National Academy Press, Washington DC.

SAS. 2001. Statistical Analysis System user's guide: Statistics Edition, SAS Institute, Inc., Cary, NC, USA.

Simons PCM, Versteegh HAJ, Jongbloed AW, Kemme PA, Slump P, Bos KD, Wolters MGE, Beudeker RF, Verschoor GJ. 1990. Improvement of phosphorus availability by microbial phytase in broilers and pigs. British Journal of Nutrition 64:525-540.

Sohail SS, Roland DA. 1999. Influence of supplemental phytase on performance of broiler four to six weeks of age. Poultry Science 76:1535-1542.

Tatlı O. 2007. Mineral fosfor kaynağı içermeyen etlik civciv rasyonunda fitaz katkısı etkinliğinin belirlenmesi (Yüksek Lisans Tezi). Adnan Menderes Üniversitesi, Sağlık Bilimleri Enstitüsü, Hayvan Besleme ve Beslenme Hastalıkları Anabilim Dalı, Aydin.

TSE. 1991. Hayvan yemleri metabolik (çevrilebilir) enerji tayini (Kimyasal Metot). Türk Standartları Enstitüsü. TS 9610. UDK 636.085. Ankara.

Tiihonen K, Kettunen H, Bento MHL, Saarinen M, Lahtinen S, Ouwehand AC, Schulze H, Rautonen N. 2010. The effect of feeding essential oils on broiler performance and gut microbiota. British Poultry Science 51:381-392.

Viveros A, Brenes A, Arija I, Centeno C. 2002. Effects of microbial phytase supplementation on mineral utilization and serum enzyme activities in broiler chicks fed different levels of phosphorus. Poultry Science 81:1172-1183. 